\title{
PEMODELAN SISTEM ANTREAN PELAYANAN BUS JALUR BARAT TERMINAL TIRTONADI KOTA SURAKARTA DENGAN METODE BAYESIAN
}

\author{
Nurul Khasanah ${ }^{1}$, Sugito $^{2}$, Yuciana Wilandari ${ }^{3}$ \\ 1,2,3 Departemen Statistika, Fakultas Sains dan Matematika, Universitas Diponegoro \\ 4nurulkhasanah@gmail.com
}

\begin{abstract}
Tirtonadi is the largest bus station in Surakarta City. The departure line is devided into two lines, namely west line and east line. The west line serves buses to the west of Surakarta City. The number of buses that enter and leave the station every day causes bus queues. Modeling the queue system and analyzing the system performance measure aims to determine wether the bus service system is good or not. The queue system model is obtained by finding the distribution of arrival patterns and service patterns using the Bayesian method. This method is used because it combines the information from the current research and the prior information from the previous research. The queueing condition of the five lanes in the west line meets steady state conditions because the utility value is less than 1 . The queue displant is First Come First Service (FCFS) with unlimited customers and unlimited calling sources. Based on the posterior distribution, the queue system of service bus is $(\mathrm{GAMM} / \mathrm{IG} / 1):(\mathrm{GD} / \infty / \infty)$ for Solo-Jakarta-Bandung lane and Pedesaan lane, while for Solo-Purwokerto-

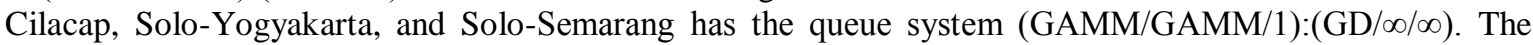
queue system of service bus for each lane has good services based on the value of system performance measure.
\end{abstract}

Keywords: Tirtonadi, queue system, Bayesian, posterior, prior, system performance measure

\section{PENDAHULUAN}

Sebagai salah satu moda transportasi yang paling sering digunakan oleh masyarakat, bus tetap menjadi pilihan untuk beraktifitas di tengah kondisi pandemi Covid-19 yang terjadi di Indonesia. Selain karena harga yang relatif terjangkau dibandingkan dengan angkutan umum yang lainnya, jadwal keberangkatan bus juga cukup banyak.

Kota Surakarta memiliki terminal bus yang menjadi terminal terbesar di Indonesia yaitu Terminal Tirtonadi yang melayani bus Antar Kota Antar Provinsi (AKAP), bus Antar Kota Dalam Provinsi (AKDP), Angkutan Kota (Angkot), Batik Solo Trans (BST), dan Bus Rapid Transit (BRT) Jateng. Pelayanan bus di Terminal Tirtonadi terbagi menjadi dua jalur yaitu jalur barat dan jalur timur. Salah satu faktor penyebab terjadinya antrean bus di jalur barat adalah adanya perubahan jadwal yang dilakukan oleh pihak Perusahaan Otobus (PO). Kondisi tersebut memicu terjadinya penumpukan bus di terminal. Penumpukan bus ini dapat menyebabkan sistem pelayanan tidak efektif. Oleh karena itu, peneliti ingin menerapkan teori antrean dengan memodelkan sistem antrean bus di jalur barat Terminal Tirtonadi Kota Surakarta, sehingga dapat ditentukan ukuran kinerja sistem untuk mengetahui efektifitas sistem pelayanan bus di Terminal Tirtonadi Kota Surakarta.

Pada penelitian sebelumnya oleh Wrediningsih (2018) sudah diperoleh model yang tepat untuk menggambarkan sistem antrean di jalur barat. Namun, seiring berjalannya waktu telah terjadi perubahan keadaan dan banyaknya penumpang, maka pemodelan sistem antrean dapat dilakukan dengan mempertimbangkan informasi dari penelitian sebelumnya. Menurut Soejati dan Soebanar (1988), metode Bayesian adalah metode yang menggabungkan informasi dari sampel dengan informasi lain yang telah tersedia sebelumnya. Dalam penelitian ini, pemodelan sistem antrean akan menggunakan metode Bayesian untuk memperoleh distribusi posterior dari pola kedatangan dan pola pelayanan. 


\section{TINJAUAN PUSTAKA}

\subsection{Tinjauan Umum Terminal Tirtonadi Kota Surakarta}

Terminal Tirtonadi merupakan terminal bus yang dijadikan sebagai Terminal Percontohan Nasional oleh Kementerian Perhubungan dan terletak di Jalan Jend. A Yani 262, Gilingan, Kecamatan Banjarsari, Kota Surakarta. Terminal bus Tirtonadi jalur barat merupakan terminal bus yang melayani penumpang dengan tujuan ke arah barat Kota Surakarta seperti Jakarta, Bandung, Purwokerto, Cilacap, Semarang, Yogyakarta, dan pedesaan. Bus yang berada di jalur barat terdapat dua jenis yaitu bus patas dan nonpatas.

\subsection{Ukuran Steady State}

Menurut Taha (1996), steady state merupakan kondisi sewaktu sifat-sifat tidak berubah dengan berjalannya waktu (konstan). $\rho$ dapat didefinisikan sebagai perbandingan antara rata-rata pelanggan yang datang dengan rata-rata pelanggan yang telah dilayani per satuan waktu dan dapat dituliskan sebagai berikut:

$$
\rho=\frac{\lambda}{c \mu}
$$

dengan $\lambda$ merupakan rata-rata benyak pelanggan yang datang per satuan waktu, $\mu$ merupakan rata-rata laju pelayanan per satuan waktu, dan $c$ merupakan banyak fasilitas pelayanan. Kondisi steady state dapat terpenuhi jika $\rho<1$.

\subsection{Uji Kecocokan Distribusi}

Uji kecocokan distribusi (goodness of fit) digunakan untuk menguji apakah sekumpulan data hasil pengamatan mengikuti distribusi tertentu. Salah satu uji kecocokan distribusi yang umum digunakan adalah uji Kolmogorv-Smirnov dengan prosedur sebagai berikut (Daniel, 1989):

a. Menentukan Hipotesis

Ho : Distribusi sampel mengikuti distribusi yang ditetapkan

$\mathrm{H}_{1}$ : Distribusi sampel tidak mengikuti distribusi yang ditetapkan

b. Menentukan Taraf Signifikansi

Taraf signifikasi yang digunakan adalah $\alpha=5 \%$

c. Statistik Uji

$$
D=\sup \left|S(x)-F_{0}(x)\right|
$$

dengan $S(x)$ adalah fungsi kumulatif yang dihitung dan $F_{0}(x)$ adalah fungsi peluang kumulatif distribusi yang dihipotesiskan

d. Kriteria Uji

Pada taraf signifikansi $\alpha$, Ho ditolak jika nilai $D \geq \operatorname{Dtabel}(1-\alpha)$ atau jika nilai sig $\leq$ nilai $\alpha$, dimana Dtabel $(1-\alpha)$ merupakan nilai kritis yang diperoleh dari tabel Kolmogorov-Smirnov.

Distribusi-distribusi yang digunakan dalam penelitian ini adalah sebagai berikut:

1. Distribusi Poisson

Menurut Walpole dan Myers (1995), variabel random X berdistribusi Poisson dengan fungsi densitas:

$$
p(x ; \lambda)=\frac{e^{-\lambda} \lambda^{x}}{x !}, x=0,1,2, \ldots
$$




\section{Distribusi Eksponensial}

Sebuah variabel random kontinu memiliki distribusi eksponensial dengan parameter $\lambda$ jika memiliki fungsi densitas sebagai berikut:

$$
f(x ; \lambda)=\left\{\begin{array}{l}
\frac{1}{\lambda} e^{-\frac{x}{\lambda}}, x>0 \\
0, \text { lainnya }
\end{array}\right.
$$

dengan $\lambda>0$ (Walpole dan Myers, 1995).

\section{Distribusi Geometrik}

Jika percobaan bebas diulang dapat menghasilkan sukses dengan peluang $\lambda$ dan gagal dengan peluang $q=1-\lambda$, maka distribusi peluang dari variabel random $X$, dengan $x$ dalah banyaknya percobaan hingga sukses pertama terjadi adalah (Walpole dan Myers, 1995):

$$
g(x ; \lambda)=\lambda(1-\lambda)^{x-1}, x=0,1,2, \ldots
$$

4. Distribusi Lognormal

Menurut Walpole dan Myers (1995), sebuah variabel random $X$ berdistribusi lognormal jika variabel random $X=\ln (X)$ berdistribusi normal dengan rata-rata $\mu$ dan standar deviasi $\sigma$. Hasil fungsi densitas dari $X$ adalah sebagai berikut:

$$
f(x ; \mu, \sigma)= \begin{cases}\frac{1}{\sqrt{2 \pi} \sigma x} e^{-\frac{1}{2 \sigma^{2}}[\ln (x)-\mu]^{2}}, & x \geq 0 \\ 0, & x<0\end{cases}
$$

\section{Distribusi Weibull}

Menurut Walpole dan Myers (1995), sebuah variabel random $X$ berdistribusi Weibull dengan parameter $\lambda$ dan $\beta$ jika fungsi densitas sebagai berikut:

$$
f(x ; \lambda, \beta)= \begin{cases}\lambda \beta x^{\beta-1} e^{-\lambda x^{\beta}}, x>0 \\ 0, & \text { lainnya }\end{cases}
$$

6. Distribusi Normal

Menurut Walpole dan Myers (1995), fungsi densitas normal dari suatu variabel random $X$ dengan rata-rata $\mu$ dan variansi $\sigma^{2}$ adalah:

$$
f(x ; \mu, \sigma)=\frac{1}{\sqrt{2 \pi} \sigma} e^{-\frac{1}{2 \sigma^{2}}(x-\mu)^{2}},-\infty<x<\infty
$$

\section{Distribusi Gamma}

Menurut Bain dan Engelhardt (1992), sebuah variabel random kontinu $X$ berdistribusi gamma dengan parameter $k>0$ dan $\theta>0$ jika memiliki bentuk pdf sebagai berikut:

$$
f(x ; \theta, k)=\frac{1}{\theta^{k} \Gamma(k)} x^{k-1} e^{-\frac{x}{\theta}}, x>0
$$

8. Distribusi Invers Gamma

Sebuah variabel acak kontinu $X$ dikatakan memiliki distribusi Invers Gamma dengan parameter bentuk $k$ dan parameter skala $\theta$, jika fungsi kepadatan probabilitas (pdf) dari $X$ sebagai berikut (Bernado dan Smith, 2000):

$$
f(x)=\left\{\begin{array}{c}
\frac{\theta^{k}}{\Gamma(k)} x^{-(k-1)} e^{-\frac{\theta}{x}}, \text { untuk } x>0 \\
0, \text { untuk } x \text { lainnya }
\end{array}\right.
$$




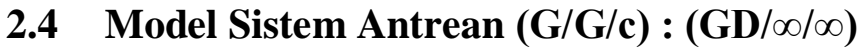

Menurut Gross dan Haris (1998) dalam Wrediningsih (20018), model antrean (G/G/c): $(\mathrm{GD} / \infty / \infty)$ adalah model antrean dengan pola kedatangan berdistribusi umum (general) dan pola pelayanan berdistribusi umum (general) dengan jumlah fasilitas pelayanan sebanyak $c$.

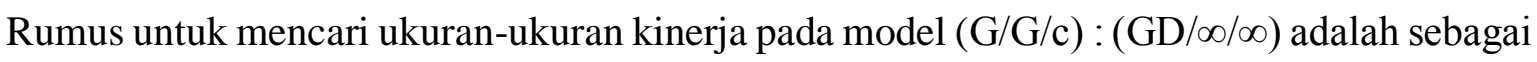
berikut:

$$
\begin{array}{ll}
L_{q}=\left(\frac{\rho r^{c}}{c !(1-\rho)^{2}}\right) P_{0} \frac{\mu^{2} v(t)+v\left(t^{\prime}\right) \lambda^{2}}{2} & W_{q}=\frac{L_{q}}{\lambda} \\
L_{s}=L_{q}+r & W_{s}=W_{q}+\frac{1}{\mu}
\end{array}
$$

dengan: $v(t)=\left(\frac{1}{\mu^{2}}\right)^{2}$ dan $v\left(t^{\prime}\right)=\left(\frac{1}{\lambda^{2}}\right)^{2}$

\subsection{Metode Bayesian}

Metode Bayesian merupakan metode yang menggabungkan pengetahuan subjektif terkait distribusi peluang dari parameter yang tidak diketahui dengan informasi yang diperoleh dari data sampel (Walpole dan Myers, 1995).

a. Distribusi Prior

Menurut Box dan Tiao (1973), distribusi prior dikelompokkan berdasarkan penentuan masing-masing parameter pada pola distribusinya menjadi dua yaitu prior informatif dan prior noniformatif. Salah satu pendekatan dari noninformatif prior adalah metode Jeffrey's.

Menurut Berger (1980), metode Jeffrey's menyatakan bahwa distribusi prior $f(\theta)$ merupakan akar kuadrat dari informasi Fisher yang dinyatakan dalam:

$$
f(\theta)=[I(\theta)]^{\frac{1}{2}}
$$

dengan: $I(\theta)=-E_{\theta}\left[\frac{\partial^{2} \log f(x ; \theta)}{\partial \theta^{2}}\right]$

b. Fungsi Likelihood

Menurut Bain dan Engelhardt (1992), fungsi likelihood adalah fungsi densitas bersama dari $n$ variabel random $X_{1}, X_{2}, \ldots, X_{n}$ dan dinyatakan dalam bentuk $f\left(x_{1}, x_{2}, \ldots, x_{n} ; \theta\right)$.

$$
\begin{aligned}
L(\theta) & =f\left(x_{1} ; \theta\right) f\left(x_{2} ; \theta\right) \ldots f\left(x_{n} ; \theta\right) \\
& =\prod_{i=1}^{n} f\left(x_{i} ; \theta\right)
\end{aligned}
$$

c. Distribusi Posterior

Fungsi densitas posterior atau pdf posterior dapat ditulis sebagai berikut (Bain dan Engelhardt, 1992):

$$
f(\theta \mid x)=\frac{f(\theta) \mathrm{L}(x \mid \theta)}{\int f(\theta) L(x \mid \theta) d \theta}
$$

dengan $f(\theta)$ adalah distribusi prior dan $\mathrm{L}(x \mid \theta)$ adalah fungsi likelihood sampel.

\section{METODE PENELITIAN}

Penelitian dilaksanakan tanggal 15-21 Februari 2021 mulai pukul 06.30-16.00 WIB setiap harinya di jalur barat Terminal Tirtonadi Kota Surakarta. Data yang digunakan adalah data primer berupa data jumlah kedatangan bus dan data waktu pelayanan bus. Stopwatch berbasis Android digunakan untuk membantu proses penelitian, sedangkan untuk mengolah data digunakan software Ms. Excel, SPSS, Easyfit 5.6 Professional, R, dan Matlab R2009a. 


\section{HASIL DAN PEMBAHASAN}

\subsection{Gambaran Umum Sistem Antrean Bus Terminal Tirtonadi Kota Surakarta}

Pelayanan bus di Terminal Tirtonadi Kota Surakarta terbagi menjadi dua jalur yaitu jalur timur dan jalur barat. Jalur barat melayani bus jurusan barat Kota Surakarta. Pada penelitian ini, permasalahan dibatasi untuk bus nonpatas di jalur barat untuk lima lajur yaitu lajur Solo-Jakarta-Bandung (A), lajur Solo-Purwokerto-Cilacap (B), lajur Solo-Yogyakarta (C), lajur Solo-Semarang (D), dan lajur Pedesaan (E). Bus jalur barat yang memasuki Terminal Tirtonadi dan menggunakan fasilitas pelayanan dianggap sebagai pelanggan, sedangkan masing-masing lajur yang terdapat di jalur barat Terminal Tirtonadi dianggap sebagai fasilitas pelayanan. Interval yang digunakan dalam peneltian ini adalah 120 menit untuk lajur A dan E, 90 menit untuk lajur B, serta 60 menit untuk lajur B, C, dan D.

\subsection{Ukuran Steady State}

Tabel 1 merupakan tabel nilai tingkat kegunaan $(\rho)$ untuk setiap lajur berdasarkan data penelitian yang diperoleh.

Tabel 1. Ukuran Steady State Jalur Barat

\begin{tabular}{lccc}
\hline Lajur & Rata-rata kedatangan & Rata-rata pelayanan & $\rho$ \\
\hline A & 3,10714 & 14,3098 & 0,37052 \\
B & 1,4048 & 37,4941 & 0,5852 \\
C & 2,3492 & 19,5376 & 0,7650 \\
D & 3,4127 & 16,5688 & 0,9424 \\
E & 2,8571 & 13,9102 & 0,3312 \\
\hline
\end{tabular}

Nilai tingkat kegunaan untuk masing-masing lajur $<1$, artinya rata-rata kedatangan bus tidak melebihi rata-rata jumlah bus yang dilayani sehingga kondisi steady state terpenuhi.

\subsection{Uji Kecocokan Distribusi Data Sampel}

Pada uji kecocokan distribusi ini akan dilakukan analisis apakah data sampel yaitu data jumlah kedatangan mengikuti distribusi Poisson dan data waktu pelayanan mengikuti distribusi Eksponensial. Uji kecocokan distribusi yang digunakan adalah uji KolmogorovSmirnov. Apabila data jumlah kedatangan tidak mengikuti distribusi Poisson atau data waktu pelayanan tidak mengikuti distribusi Eksponensial maka dilakukan uji kecocokan distribusi lainnya hingga diperoleh distribusi yang paling sesuai.

a. Uji Kecocokan Distribusi Data Jumlah Kedatangan Bus

Uji kecocokan distribusi Poisson untuk masing-masing lajur dilakukan dengan $\mathrm{H}_{0}$ yaitu data jumlah kedatangan bus berdistribusi Poisson dan $\mathrm{H}_{1}$ yaitu data jumlah kedatangan bus tidak berdistribusi Poisson. Jika digunakan $\alpha=5 \%$ maka diperoleh hasil pada Tabel 2.

Tabel 2. Uji Kecocokan Distribusi Poisson Data Jumlah Kedatangan Bus

\begin{tabular}{lccc}
\hline Lajur & $D$ & $\mathrm{D}_{\text {tabel }}(1-\alpha)$ & Keputusan \\
\hline $\mathrm{A}$ & 0,173 & 0,250 & $\mathrm{H}_{0}$ diterima karena $\mathrm{D}<\mathrm{D}_{\text {tabel }}(1-\alpha)$ \\
$\mathrm{B}$ & 0,126 & 0,210 & $\mathrm{H}_{0}$ diterima karena $\mathrm{D}<\mathrm{D}_{\text {tabel }}(1-\alpha)$ \\
$\mathrm{C}$ & 0,082 & 0,171 & $\mathrm{H}_{0}$ diterima karena $\mathrm{D}<\mathrm{D}_{\text {tabel }}(1-\alpha)$ \\
$\mathrm{D}$ & 0,115 & 0,171 & $\mathrm{H}_{0}$ diterima karena $\mathrm{D}<\mathrm{D}_{\text {tabel }}(1-\alpha)$ \\
$\mathrm{E}$ & 0,083 & 0,250 & $\mathrm{H}_{0}$ diterima karena $\mathrm{D}<\mathrm{D}_{\text {tabel }}(1-\alpha)$ \\
\hline
\end{tabular}


Berdasarkan Tabel 2 dapat disimpulkan bahwa data jumlah kedatangan bus untuk semua lajur berdistribubsi Poisson.

b. Uji Kecocokan Distribusi Waktu Pelayanan Bus

Uji kecocokan distribusi Eksponensial untuk masing-masing lajur dilakukan dengan $\mathrm{H}_{0}$ adalah data jumlah kedatangan bus berdistribusi Eksponensial dan $\mathrm{H}_{1}$ adalah data jumlah kedatangan bus tidak berdistribusi Eksponensial. Jika digunakan $\alpha=5 \%$ maka diperoleh hasil pada Tabel 3.

Berdasarkan Tabel 3 dapat disimpulkan bahwa data waktu pelayanan bus untuk semua lajur tidak berdistribusi Eksponensial sehingga dilakukan uji distribusi lainnya dengan software Easyfit dan diperoleh hasil dalam Tabel 4.

Tabel 3. Uji Kecocokan Distribusi Eksponensial Data waktu Pelayanan Bus

\begin{tabular}{cccc}
\hline Jalur & $D$ & $\mathrm{D}_{\text {tabel }}(1-\alpha)$ & \multicolumn{1}{c}{ Keputusan } \\
\hline A & 0,225 & 0,146 & $\mathrm{H}_{0}$ ditolak karena D $>\mathrm{D}_{\text {tabel }}(1-\alpha)$ \\
B & 0,202 & 0,177 & $\mathrm{H}_{0}$ ditolak karena D $>\mathrm{D}_{\text {tabel }}(1-\alpha)$ \\
C & 0,286 & 0,112 & $\mathrm{H}_{0}$ ditolak karena D $>\mathrm{D}_{\text {tabel }}(1-\alpha)$ \\
D & 0,263 & 0,093 & $\mathrm{H}_{0}$ ditolak karena D $>\mathrm{D}_{\text {tabel }}(1-\alpha)$ \\
E & 0,181 & 0,180 & $\mathrm{H}_{0}$ ditolak karena D $>\mathrm{D}_{\text {tabel }}(1-\alpha)$ \\
\hline
\end{tabular}

Tabel 4. Uji Kecocokan Distribusi General Data waktu Pelayanan Bus

\begin{tabular}{ccccc}
\hline Jalur & Distribusi & $D$ & $\mathrm{D}_{\text {tabel }}(1-\alpha)$ & Keputusan \\
\hline A & Normal & 0,1099 & 0,146 & $\mathrm{H}_{0}$ ditolak karena $\mathrm{D}<\mathrm{D}_{\text {tabel }}(1-\alpha)$ \\
B & Weibull & 0,1500 & 0,177 & $\mathrm{H}_{0}$ ditolak karena $\mathrm{D}<\mathrm{D}_{\text {tabel }}(1-\alpha)$ \\
$\mathrm{C}$ & Weibull & 0,1049 & 0,112 & $\mathrm{H}_{0}$ ditolak karena $\mathrm{D}<\mathrm{D}_{\text {tabel }}(1-\alpha)$ \\
$\mathrm{D}$ & Weibull & 0,0731 & 0,093 & $\mathrm{H}_{0}$ ditolak karena $\mathrm{D}<\mathrm{D}_{\text {tabel }}(1-\alpha)$ \\
E & Normal & 0,0962 & 0,180 & $\mathrm{H}_{0}$ ditolak karena $\mathrm{D}<\mathrm{D}_{\text {tabel }}(1-\alpha)$ \\
\hline
\end{tabular}

Berdasarkan Tabel 4 dapat disimpulkan bahwa data waktu pelayanan bus untuk lajur A dan E berditribusi Normal, sedangkan untuk lajur B, C, dan D berdistribusi Weibull.

\subsection{Distribusi Prior Noninformatif}

Informasi prior yang digunakan dalam penelitian ini adalah data jumlah kedatangan bus dan data waktu pelayanan bus pada penelitian yang dilakukan oleh Wrediningsih (2018). Data tersebut dilakukan uji Kolmogorov-Smirnov dan diperoleh kesimpulan bahwa untuk data jumlah kedatangan bus semua lajur berdistribusi Poisson kecuali lajur A yaitu berdistribusi Geometrik. Data waktu pelayanan bus untuk lajur A dan E berdistribusi Lognormal, sedangkan untuk lajur B, C, dan D berdistribusi Weibull.

Jenis informasi prior dari penelitian Wrediningsih (2018) adalah prior noninformatif karena tidak diketahui lebih lanjut terkait informasi parameternya. Salah satu pendekatan untuk menaksir parameter dari distribusi noninformatif adalah metode Jeffrey's. Berikut perhitungan prior noninformative untuk beberapa distribusi:

a. Prior Noninformatif dari Distribusi Geometrik

Prior noninormatif dengan metode Jeffrey's dari data jumlah kedatangan bus yang berdistribusi Geometrik adalah sebagai berikut:

$$
f(\lambda)=\sqrt{\frac{1}{\lambda^{2}(1-\lambda)}} \propto \frac{1}{\lambda(1-\lambda)^{1 / 2}}
$$

b. Prior Noninformatif dari Distribusi Poisson 
Prior noninormatif dengan metode Jeffrey's dari data jumlah kedatangan bus yang beridstribusi Poisson adalah sebagai berikut:

$$
f(\lambda)=\sqrt{\frac{1}{\lambda}} \propto \lambda^{-1 / 2}
$$

c. Prior Noninformatif dari Distribusi Lognormal

Prior noninormatif dengan metode Jeffrey's dari data waktu pelayanan bus yang beridstribusi Lognormal adalah sebagai berikut:

$$
f\left(\sigma^{2}\right)=\sqrt{\frac{1}{2 \sigma^{4}}} \propto \frac{1}{\sigma^{2}}
$$

Nilai noninformatif untuk $f(\mu)=c$ (konstan), sehingga

$$
f(\vartheta)=c \times \frac{1}{\sigma^{2}} \propto \frac{1}{\sigma^{2}}
$$

(Diana dan Soehardjoepri, 2016)

d. Prior Noninformatif dari Distribusi Weibull

Prior noninormatif dengan metode Jeffrey's dari data waktu pelayanan bus yang beridstribusi Weibull adalah sebagai berikut:

$$
f(\lambda)=\sqrt{\frac{1}{\lambda^{2}}}=\frac{1}{\lambda}
$$

Nilai noninformatif prior untuk $f(\beta)=c$ (konstan), sehingga

$$
f(\vartheta)=c \times \frac{1}{\lambda} \propto \frac{1}{\lambda}
$$

(Ahmed et al, 2010)

\subsection{Fungsi Likelihood}

Berdasarkan hasil penelitian untuk data jumlah kedatangan bus dan waktu pelayanan bus diperoleh fungsi likelihood untuk distribusi sampel sebagai berikut:

a. Fungsi Likelihood Distribusi Poisson

$$
L(x ; \lambda)=\prod_{i=1}^{n} \frac{e^{-\lambda} \lambda^{x}}{x !}=\frac{e^{-n \lambda} \lambda^{\sum x i}}{\prod x_{i} !}
$$

b. Fungsi Likelihood Distribusi Weibull

$$
L(x ; \lambda, \beta)=\prod_{i=1}^{n} \lambda \beta x^{\beta-1} e^{-\lambda x^{\beta}}=\lambda^{n} \beta^{n} \prod_{i=1}^{n}\left(x_{i}\right)^{\beta-1} e^{-\lambda \sum_{i=1}^{n}\left(x_{i}\right)^{\beta}}
$$

c. $\quad$ Fungsi Likelihood Distribusi Normal

$$
L\left(x ; \mu, \sigma^{2}\right)=\prod_{i=1}^{n} \frac{1}{\sqrt{2 \pi \sigma^{2}}} e^{-\frac{1}{2 \sigma^{2}}[x-\mu]^{2}}=\left(2 \pi \sigma^{2}\right)^{-\frac{n}{2}} \exp \left(-\frac{1}{2 \sigma^{2}} \sum_{i=1}^{n}\left[x_{i}-\mu\right]^{2}\right)
$$

\subsection{Distribusi Posterior}

Setelah memperoleh fungsi likelihood dari distribusi sampel dan distribusi prior noninformatif dari penelitian sebelumnya, maka dapat ditentukan distribusi posterior sebagai berikut: 
a. Distribusi Posterior dari Prior Noninformatif Distribusi Geometrik dan Likelihood Poisson

Fungsi densitas posterior untuk data prior yang berdistribusi geometrik dan fungsi likelihood dari data sampel yang berdistribusi Poisson adalah sebagai berikut:

Distribusi posterior $f(\lambda \mid \mathrm{x})$ :

$$
f(\lambda \mid \mathrm{x})=\frac{q^{-1 / 2} \frac{e^{-n \lambda_{\lambda} \sum x i-1}}{\Pi x_{i} !}}{\frac{q^{-1 / 2}}{\Pi x_{i} ! n \sum x i} \Gamma\left(\sum x i\right)}=\frac{n^{\Sigma x i}}{\Gamma\left(\sum x i\right)} e^{-n \lambda} \lambda^{\sum x i-1}
$$

Sehingga posterior $\propto \operatorname{Gamma}\left(\frac{1}{n}, \sum x i\right)$

b. Distribusi Posterior dari Prior Noninformatif Distribusi Poisson dan Likelihood

Poisson

Fungsi densitas posterior untuk data prior yang berdistribusi poisson dan fungsi likelihood dari data sampel yang berdistribusi Poisson adalah sebagai berikut:

Distribusi posterior $f(\lambda \mid x)$ :

$$
f(\lambda \mid x)=\frac{\frac{e^{-n \lambda} \lambda \sum x i-1 / 2}{\Pi x_{i} !}}{\frac{1}{\prod x_{i} ! n^{\sum x i+\frac{1}{2}}} \Gamma\left(\sum x i+\frac{1}{2}\right)}=\frac{n^{\sum x i+\frac{1}{2}}}{\Gamma\left(\sum x i+\frac{1}{2}\right)} e^{-n \lambda} \lambda^{\sum x i-1 / 2}
$$

Sehingga posterior $\propto \operatorname{Gamma}\left(\frac{1}{n}, \sum x i+\frac{1}{2}\right)$

c. Distribusi Posterior dari Prior Noninformatif Distribusi Weibull dan Likelihood Weibull

Fungsi densitas posterior dari prior prior noniformatif distribusi Weibull dan likelihood Weibull dengan melakukan transformasi fungsi padat peluang distribusi Weibull ke dalam bentuk Eksponensial menggunakan transformasi Jacobian dengan mengubah $x^{\beta}$ menjadi $y$ sebagai berikut:

Distribusi posterior $f(\lambda \mid y)$ :

$$
f(\lambda \mid y)=\frac{\lambda^{n-1} e^{-\lambda \Sigma_{i=1}^{n} y_{i}}}{\frac{2}{\left(\sum_{i=1}^{n} y_{i}\right)^{n} \Gamma(n)}}=\frac{\left(\sum_{i=1}^{n} y_{i}\right)^{n}}{2 \Gamma(n)} \lambda^{n-1} e^{-\lambda \sum_{i=1}^{n} y_{i}}
$$

karena $y=x^{\beta}$, maka:

$$
f(\lambda \mid y)=\frac{\left(\sum_{i=1}^{n} x_{i}^{\beta}\right)^{n}}{2 \Gamma(n)} \lambda^{n-1} e^{-\lambda \sum_{i=1}^{n} x_{i}{ }^{\beta}}
$$

Sehingga posterior $\propto \operatorname{Gamma}\left(n,\left(\sum_{i=1}^{n}\left(x_{i}\right)^{\beta}\right)^{-1}\right)$

d. Distribusi Posterior dari Prior Noninformatif Distribusi Lognormal dan Likelihood Normal

Fungsi densitas posterior untuk data prior yang berdistribusi Lognormal dan fungsi likelihood dari data sampel yang berdistribusi Normal adalah sebagai berikut:

Distribusi Posterior $f\left(\mu, \sigma^{2} \mid x\right)$ :

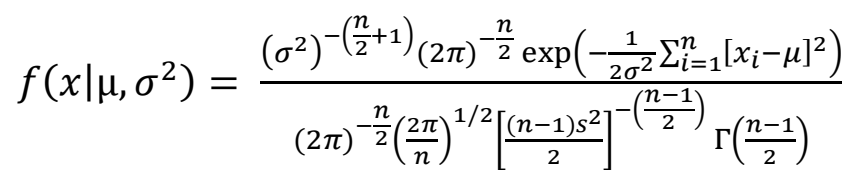




$$
=\left(\frac{n}{2 \pi}\right)^{\frac{1}{2}}\left[\frac{(n-1) s^{2}}{2}\right]^{\left(\frac{n-1}{2}\right)}\left[\Gamma\left(\frac{n-1}{2}\right)\right]^{-1}\left(\sigma^{2}\right)^{-\left(\frac{n}{2}+1\right)} \exp \left(-\frac{1}{2 \sigma^{2}} \sum_{i=1}^{n}\left[x_{i}-\mu\right]^{2}\right)
$$

Sehingga posterior $\propto$ Invers Gamma $\left(\frac{n}{2}, \frac{1}{2} \sum_{i=1}^{n}\left[x_{i}-\mu\right]^{2}\right)$

\subsection{Model Sistem Antrean}

Berdasarkan analisis distribusi posterior yang telah dilakukan maka diperoleh model sistem antrean bayesian pada Tabel 5 .

Tabel 5. Model Sistem Antrean Bayesian

\begin{tabular}{|c|c|c|c|}
\hline Lajur & $\begin{array}{c}\text { Distribusi } \\
\text { Kedatangan }\end{array}$ & $\begin{array}{l}\text { Distribusi } \\
\text { Pelayanan }\end{array}$ & Model Sistem Antrean \\
\hline A & Gamma & Invers Gamma & $(\mathrm{GAMM} / \mathrm{IG} / 1):(\mathrm{GD} / \infty / \infty)$ \\
\hline B & Gamma & Gamma & $(\mathrm{GAMM} / \mathrm{GAMM} / 1):(\mathrm{GD} / \infty / \infty)$ \\
\hline $\mathrm{C}$ & Gamma & Gamma & $(\mathrm{GAMM} / \mathrm{GAMM} / 1):(\mathrm{GD} / \infty / \infty)$ \\
\hline $\mathrm{D}$ & Gamma & Gamma & $(\mathrm{GAMM} / \mathrm{GAMM} / 1):(\mathrm{GD} / \infty / \infty)$ \\
\hline $\mathrm{E}$ & Gamma & Invers Gamma & $(\mathrm{GAMM} / \mathrm{IG} / 1):(\mathrm{GD} / \infty / \infty)$ \\
\hline
\end{tabular}

\subsection{Ukuran Kinerja Sistem}

Berdasarkan hasil distribusi posterior, maka dilakukan pembangkitan data sesuai dengan distribusi posterior. Selanjutnya, data ini digunakan untuk menghitug ukuran kinerja sistem. Tabel 6 adalah output GUI MATLAB untuk masing-masing lajur.

Tabel 6. Ukuran Kinerja Sistem

\begin{tabular}{cccccc}
\hline Lajur & $P_{0}$ & $L_{q}$ & $L_{s}$ & $W_{q}$ & $W_{s}$ \\
\hline A & 0,9999 & $2,981 \times 10^{-15}$ & $2,962 \times 10^{-6}$ & $7,771 \times 10^{-17}$ & $7,722 \times 10^{-8}$ \\
B & 0.8701 & $1,891 \times 10^{-6}$ & 0,1166 & $2,967 \times 10^{-8}$ & 0,0018 \\
C & 0,5746 & $8,092 \times 10^{-5}$ & 0,3312 & $2,604 \times 10^{-6}$ & 0,0101 \\
D & 0,7531 & $6,340 \times 10^{-5}$ & 0,2065 & $3,097 \times 10^{-6}$ & 0,0101 \\
E & 0,9999 & $8,863 \times 10^{-15}$ & $7,910 \times 10^{-6}$ & $1,492 \times 10^{-16}$ & $1,331 \times 10^{-7}$ \\
\hline
\end{tabular}

\section{KESIMPULAN}

Berdasarkan hasil dan pembahasan dapat disimpulkan bahwa model sistem antrean pelayanan bus untuk masing-masing lajur yaitu lajur A (Solo-Jakarta-Bandung) dan lajur E

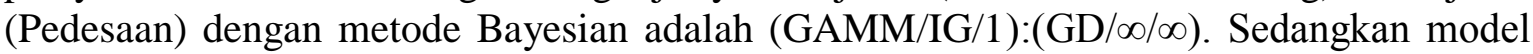
sistem antrean pelayanan bus untuk masing-masing lajur yaitu lajur B (Solo-PurwokertoCilacap), lajur C (Solo-Yogyakarta), dan lajur D (Solo-Semarang) dengan metode Bayesian

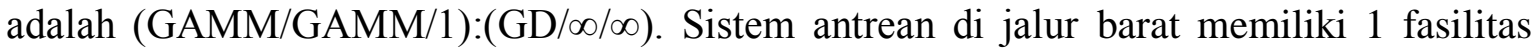
pelayanan untuk masing-masing lajur dengan disiplin pelayanan First Come First Service $(F C F S)$ serta jumlah kapasitas pelanggan dan sumber pemanggilan tidak terbatas. Secara keseluruhan sistem antrean pelayanan bus di jalur barat Terminal Tirtonadi Kota Surakarta sudah baik dan sudah efektif berdasarkan nilai ukuran kinerja sistem yang telah diperoleh.

\section{DAFTAR PUSTAKA}

Ahmed, A.O.M., Al-Kutubi, H.S., Ibrahim, N.A. 2010. Comparison of the Bayesian and Maximum Likelihood Estimation for Weibull Distribution. Journal of Mathematics and Statistics Vol 6, No. 2, Hal: 100-104. 
An. 2017. Tirtonadi Surakarta, Terminal Modern Dilengkapi Skybridge. https://www.beritatrans.com/artikel/96143/-Tirtonadi-Surakarta-Terminal-ModernDilengkapi-Skybridge/ (1 Februari 2021).

Bain, L. J. dan Engelhardt, M. 1992. Introduction Probability and Mathematical Statistics Second Edition. California: Duxburry Press.

Berger, J. O. 1980. Statistical Decision Theory and Bayesian Analysis Second Edition. New York: Springel-Verlag.

Bernado, J.M. dan Smith, A.F.M. 2000. Bayesian Theory. Chichester: Jhon Wiley and Sons, Ltd.

Box, G. E. P. dan Tiao, G.C. 1973. Bayesian Inference in Statistical Analysis. Philippines: Addision-Wesley Publishing Company.

Daniel, W. 1989. Statistika Non Parametrik Terapan (Terjemahan). Jakarta: PT. Gramedia.

Diana, E.N. dan Soehardjoepri. 2016. Pendekatan Metode Bayesian untuk Kajian Estimasi Parameter Distribusi Log-Normal untuk Noninformatif Prior. Jurnal Sains dan Seni ITS Vol 5, No. 2, Hal: A14-A16.

Gross, D. dan Harris, C. M. 1998. Fundamental of Queueing Theory: Third Edition. New York: Jhon Willey and Sons, Inc.

Soejati, Z. dan Soebanar. 1988. Inferensi Bayesian. Jakarta: Karunika.

Taha, H. A. 1996. Riset Operasi: Jilid Dua. Jakarta: Binarupa Aksara.

Walpole, R. E. dan Myers, R. H. 1995. Probability and Statistics for Engineers and Scientists Ninth Edition. United States of America: Pearson Education.

Wrediningsih, A.P., Sugito, Pruhatama, A. 2018. Identifikasi Model Antrean Non-Poisson (Studi Kasus: Bus Nonpatas Antarkota Antarprovinsi (AKAP) dan Antarkota Dalam Provinsi (AKDP) Lajur Barat Terminal Bus Tirtonadi Surakarta. Jurnal Statistika Universitas Muhammadiyah Semarang Vol. 6, No. 2. 